\title{
Recent Advances in the Understanding and Treatment of Trichotillomania
}

\author{
Michael R. Walther, B.S., Emily J. Ricketts, B.A., Christine A. Conelea, M.S., and Douglas \\ W. Woods, Ph.D. \\ University of Wisconsin-Milwaukee
}

\begin{abstract}
Trichotillomania (TTM), or chronic hair pulling, is associated with significant levels of distress and impairment. While research is in its infancy, more data are accumulating regarding the impact, phenomenology, maintaining variables, etiology, and treatment of TTM. Behavior therapy and clomipramine have been moderately effective in reducing TTM symptoms in clinical trials. Enhancing behavior therapy with techniques designed to address TTM patients' emotional control tendencies (e.g., acceptance-based procedures) represents a promising direction in treating TTM.
\end{abstract}

\section{Keywords}

Trichotillomania; behavior therapy; ACT; OCD-spectrum; impulse-control disorder

This paper summarizes existing research on trichotillomania (TTM) in adults and describes how basic psychopathology research on TTM led to the modification of existing behavioral treatment procedures to create a novel acceptance-based intervention. Issues surrounding the diagnosis of TTM will be discussed first, followed by a brief review of the literature on TTM's epidemiology, impact, and phenomenology. After highlighting common assessment techniques and tools used in TTM, etiology of the disorder will be discussed. Finally, treatments for TTM are discussed and steps taken to modify these interventions in the light of recent etiological work are described.

\section{Definition of TTM}

Trichotillomania is characterized by repetitive hair pulling that results in noticeable hair loss (Diagnostic and Statistical Manual, $4^{\text {th }}$ edition - text revision; American Psychiatric Association, 2000). The DSM-IV-TR also specifies criterion B: tension prior to pulling and criterion C: relief, pleasure, or reduced tension post pulling, but the validity of these is suspect because many who pull do not report the presence of both criteria (Hanna, 1997; Reeve, Bernstein, \& Christenson, 1992). Although TTM is included in the DSM-IV-TR as an impulse control disorder, researchers have also construed it as an obsessive-compulsive

Correspondence concerning this article can be addressed to Dr. Douglas W. Woods, Ph.D.; 2441 E. Hartford Avenue, Room 358; University of Wisconsin-Milwaukee; Milwaukee, WI 53211. dwoods@uwm.edu.

Michael R. Walther, Emily J. Ricketts, Christine A. Conelea, and Douglas W. Woods, Department of Psychology, University of

Wisconsin-Milwaukee. 
spectrum disorder (Stein, Lochner, Hemmings, \& Kinnear, 2005) or addictive disorder (Grant, Odlaug, \& Potenza, 2007).

\section{Epidemiology}

No rigorous epidemiological studies have been conducted, but TTM estimates suggest a prevalence of $0.6 \%$ to $~ 3 \%$ depending on whether full DSM-IV-TR criteria are used (Christenson, Pyle, \& Mitchell, 1991; Stanley, Borden, Bell, \& Wagner, 1994). TTM is more common in females (Cohen, Stein, Simeon, \& Spadaccini, 1995; Swedo \& Leonard, 1992), and onset is usually in early adolescence (Christenson, Mackenzie, et al., 1991). Some researchers have suggested a possible bimodal age of onset, with a subgroup of individuals, known as "baby trichs," whose onset occurs in childhood and whose symptoms may be less enduring and contain fewer comorbidities (Winchel, 1992). Because "baby trichs" have been hypothesized to have milder symptoms than those with adolescent onset, some have hypothesized they are more responsive to behavior modification techniques, whereas adolescents and adults may need a more comprehensive treatment package like cognitive-behavioral therapy (Wetterneck \& Woods, 2007). No data from treatment studies support such hypotheses, but research has identified important developmental aspects of TTM that are consistent with those notions. Flessner, Woods, Franklin, Keuthen, and Piacentini (2009) compared pulling styles and other phenomena in those with TTM across age groups, and reported that "automatic" pulling, or pulling that occurs outside of one's awareness, is predominant in children (age 10 to 12). Conversely, "focused" pulling, which is pulling in response to emotional or cognitive stimuli, was found to be more prevalent amongst adolescents and adults.

\section{Impact}

TTM has a significant impact on the lives of individuals with the disorder. In adults, it leads to deficits in psychological, social, academic, and occupational functioning. Individuals with TTM commonly experience negative affect and negative self-evaluations including low selfesteem, feelings of unattractiveness, embarrassment, shame, guilt, isolation, pain, fear, and concern regarding the concealment of the disorder (Casati, Toner, \& Yu, 2000; Diefenbach, Tolin, Hannan, Crocetto, \& Worhunsky, 2006; du Toit, van Kradenburg, Niehaus, \& Stein, D. J., 2001; Soriano, et al., 1996; Stemberger, Thomas, Mansueto, \& Carter, 2000). Anger and frustration due to an inability to control pulling symptoms is also common (Casati et al.). A small subset of adults with TTM use alcohol, tobacco, or drugs to reduce negative feelings associated with hairpulling or to reduce urges to pull (Woods, Flessner, et al., 2006).

TTM also interferes with social functioning, as many individuals experience lowered frequency, quantity, and quality of friendships, dating, and intimate relationships (Keuthen et al., 2004; Wetterneck, Woods, Norberg, \& Begotka, 2006). Many individuals with TTM attempt to disguise the bald patches by wearing certain hairstyles or wigs, or through the use of cosmetics. (Casati et al., 2000; Diefenbach et al., 2006; du Toit et al., 2001). Some avoid visits to the hairdresser for fear of being exposed (Diefenbach et al; du Toit et al; Stemberger et al; Wetterneck et al., 2006) and avoid social or recreational activities (i.e., 
vacations, entertainment, swimming, sports, going outside on windy days) where hair loss is noticeable (Casati et al; Diefenbach et al; Stemberger et al; Wetterneck et al; Woods, Flessner, et al., 2006).

Trichotillomania significantly impacts academic and occupational performance and finances. TTM may lead to school absences, difficulty performing school duties, and difficulty studying (Wetterneck et al., 2006; Woods, Flessner, et al., 2006). Many individuals with TTM experience occupational interference, particularly in work productivity, concentration, and career advancement (Diefenbach et al., 2006; Keuthen et al., 2004; Wetterneck et al., 2006; Woods, Flessner, et al., 2006). Financially, TTM results in money spent on concealment and treatment (Wetterneck et al.). Research on the impact of TTM in children indicates that children with the disorder experience similar interference as adults (Franklin et al., 2008).

There is a paucity of research on the cross-cultural impact of TTM; however findings from two studies of African American women with TTM show that the individuals experienced feelings of guilt following a pulling episode, embarrassment due to the effects of pulling, and social avoidance (Neal-Barnett \& Stadulis, 2006; Neal-Barnett, Ward-Brown, Mitchell, \& Krownapple, 2000).

\section{Phenomenology}

Individuals with TTM may pull hair from any part of the body, but the scalp is the most common pulling site, followed by eyelashes and eyebrows (Franklin et al., 2008; Hanna, 1997). Pulling of pubic hair has also been reported in those who have reached puberty, with reports ranging as high as above 50\% in anonymous surveys (Woods, Flessner, et al., 2006). Males with TTM commonly pull from the beard and/or mustache (du Toit et al., 2001). The majority of individuals in TTM samples report pulling from multiple sites (Christenson, Mackenzie, et al., 1991; du Toit et al., 2001). Though the primary method of hair extraction is with the fingertips, those with TTM may also pull with tweezers, combs, or brushes (Woods, Flessner, et al., 2006).

Trichotillomania is commonly preceded by a number of environmental factors (i.e., antecedents) and met with a variety of consequences, which are believed to play a role in the maintenance of the disorder.

\section{Antecedents}

Antecedents to pulling have been discovered across multiple phenomenological domains, including sensory stimulation, emotions, and cognitions.

Sensory-Some adults with TTM pull hairs that are different from others in terms of hair thickness, length, or location (Stein, Christenson \& Hollander, 1999). These hairs may be targeted by engaging in pre-pulling behaviors such as scanning for the "right" hair (Mansueto, Townsley-Stemberger, McCombs-Thomas, \& Goldfinger-Golomb, 1997). Physical sensations on the scalp, such as itchiness, irritation, and skin sensitivity may serve as antecedents to pulling (Christenson \& Mansueto, 1999). A study containing a college 
sample suggested that African American women may be more likely than others to pull in response to skin irritation (McCarley, Spirrson, \& Ceminsky, 2002).

Emotional-A number of studies using patient self-report have identified anxiety as a trigger to pulling. For example, $83 \%$ of an adult TTM sample reported anxiety prior to pulling (du Toit et al., 2001). Other emotional states, such as boredom, tension, and anger (Christenson, Ristvedt, \& Mackenzie, 1993; Diefenbach, Mouton-Odum, \& Stanley, 2002; Diefenbach, Tolin, Meunier, \& Worhunsky, 2008), have been associated with increased pulling in adults. In children and adolescents, findings for antecedent tension are mixed, with some studies finding the majority of children and adolescents endorsing tension (Franklin et al., 2008; King, Scahill et al., 1995) and others finding no link between tension and pulling (Hanna, 1997; King, Zohar et al., 1995; Reeve et al., 1992).

Cognitive-Thoughts about hairs or about pulling hairs, such as "this hair is out of place" or "I just need to pull a little to relieve my stress" may also precede pulling (Mansueto et al., 1997). Other cognitions that may be involved in the maintenance of TTM include rigid thinking patterns (e.g., "Wiry hairs are bad") and cognitive errors such as catastrophizing (e.g., "I cannot feel better until this hair is gone") and overgeneralizing (e.g., "This funnylooking hair is noticeable to everyone"). In addition, beliefs about appearance and fears of negative evaluation are associated with TTM severity (Norberg, Wetterneck, Woods, \& Conelea, 2007). It is unclear how closely related thoughts like these are to obsessions found in OCD, but from a behavioral conceptualization, cognitions like these may function as conditioned aversive stimuli that evoke behavior, which has historically produced the removal of the aversive thought (Wetterneck \& Woods, 2007).

\section{Consequences}

Environmental variables also follow pulling, and these consequences have been broken down into sensory, emotional, and cognitive factors.

Sensory-Sensory consequences can be broken down into two categories, tactile and visual consequences. Tactile. Tactile consequences involve reinforcement resulting from physical touch, typically produced by the manipulation of pulled hair (Rapp, Miltenberger, Galensky, Ellingson, and Long, 1999). As mentioned previously, certain types of hairs may be targeted by an individual for pulling. These may include coarse hairs or those of differing length. Many individuals with TTM report engaging in post-pulling activities that produce physical sensations that function as reinforcers (i.e., rubbing the hair between one's fingers or rubbing the hair across one's face). Though relatively rare, some with TTM ingest the hair after it has been pulled (Bouwer \& Stein, 1998). More commonly, at least half of individuals with TTM engage in other oral behavior such as biting off the root of the hair or rubbing the hair along one's lips or mouth (Christenson, Mackenzie, et al., 1991;

Christenson \& Mansueto, 1999). Visual. After the hair has been pulled, the individual may engage in behaviors such as scanning the hair, looking at the root, looking at the thickness of the hair, or other visual behaviors. These behaviors likely produce visual stimulation that reinforces the pulling. For example, finding the hair that was "out of place," gray, or that 
possessed the "important" physical feature (thickness, etc.), may function to strengthen pulling.

Emotional-Some individuals report pleasure while pulling (Mansueto et al., 1997), and others report a reduction of aversive emotional states, such as anxiety, sadness, boredom, tension, and stress pre-to-during pulling (Diefenbach et al., 2002; Diefenbach et al., 2008). However, an increase in some of those emotions, such as sadness or guilt, has been observed from during-to-post pulling (Diefenbach et al.).

Cognitive-Cognitions associated with the emotional consequences discussed above may also result from pulling. For example, cognitions associated with sadness or guilt may assist in terminating a pulling episode (Mansueto et al., 1997).

\section{Assessment}

Accurate and thorough assessment of TTM symptoms in adults and children is essential to both understanding and treating TTM. Several methods of assessment have been utilized in treatment including direct observation, clinician rating scales, and self-report measures.

Direct observation of hairpulling by an independent rater is often only utilized with children or individuals with mental retardation. Though such approaches provide objective measures of hair pulling, adults and adolescents' tendency to pull in private and the embarrassment they experience surrounding the direct observation strategy usually prevents the use of this method in such populations. As a result, self-monitoring involving the detection and recording of instances of hairpulling during certain periods of the day, is commonly used in older children and adults. Methods of self-monitoring include, saving and counting the pulled hairs, rating urges to pull, recording instances of hand-to-hair contact, or noting the context in which pulling behavior occurs. Self-monitoring is especially helpful in increasing awareness of pulling in those who lack awareness of their behavior (Diefenbach, Reitman, \& Williamson, 2000; Rothbaum \& Ninan, 1994; Stanley, Bowers, Swann, \& Taylor, 1991).

Clinician rating scales are completed by a therapist or independent evaluator and consist of questions directed toward the client regarding hairpulling symptoms. The most commonly used clinician rating scale for TTM is the National Institute of Mental Health Trichotillomania Symptom Severity and Impairment Scale (NIMH-TSS/TIS; Swedo et al., 1989). The NIMH-TSS is a 5-item measure assessing average hairpulling episode duration during the past week and on the previous day, thoughts preceding the pulling episode, resistance to urges, distress, and interference. The NIMH-TIS is an 11 point scale assessing overall patient impairment. The psychometric properties of the NIMH scales are mixed, demonstrating good interrater reliability, concurrent validity, and sensitivity to hairpulling symptom changes post treatment, but more moderate internal consistency (Diefenbach, Tolin, Crocetto, Maltby, \& Hannan, 2005; Rothbaum, 1992; Stanley, Breckenridge, Snyder, \& Novy, 1999; Swedo et al., 1989).

Objective self-report measures are completed by the patient and/or their caregiver. The most commonly used self-report measure is the Massachusetts General Hospital Hairpulling Symptom Severity Scale (MGH-HS; Keuthen et al., 1995), a 7-item measure assesses urge 
frequency, intensity, and controllability, hairpulling frequency, resistance, and controllability, and associated distress during the prior week. The MGH-HS possesses the strongest psychometric properties of any current TTM measure for adults (Diefenbach et al., 2005; Keuthen, Flessner, et al., 2007; O'Sullivan et al., 1995). TTM severity in children can be assessed with the psychometrically acceptable Trichotillomania Scale for Children (TSC; Tolin et al., 2008).

Most existing measures of TTM have focused on the assessment of pulling severity. However, recent studies have placed an emphasis on the development of assessments that distinguish between the specific pulling subtypes: focused and automatic. The Milwaukee Inventory for Styles of TTM-Child Version (MIST-C; Flessner et al., 2007) and the Milwaukee Inventory for Subtypes of TTM-Adult Version (MIST-A; Flessner et al., 2008) have demonstrated adequate internal consistency and good construct and discriminant validity in preliminary research.

\section{Etiology}

The precise etiology of TTM has yet to be determined, but possible etiological factors from several theoretical perspectives have been proposed. These factors are highlighted below.

\section{Animal models}

Plucking and pulling behaviors have been observed across many species in captivity, including rodents, birds, and mammals (Reinhardt, 2005). In one of the more promising animal models, researchers have postulated that the phenomenon of "barbering" in mice is homologous to TTM (Garner, Weisker, Dufour, \& Mench, 2004). Barbering has been found to be about one-and-a-half times more likely in female mice and five times more likely in breeder mice, consistent with the notion that TTM is more common in females. Research on the etiology of barbering has revealed several possible environmental and pathophysiological mechanisms. Barbering seems to be elevated in animals that endure social stress in the form of isolation or crowding and in animals with heightened stress reactivity (Dufour \& Garner, in press). Neuropsychological tests of barbering mice have revealed a selective deficit in "set shifting," a function controlled by the prefrontal corticostriatal loop (Garner, Meehan, Famula, \& Mench, 2006), and the severity of barbering was correlated with the severity of this deficit. Interestingly, research on the neuropsychological profiles of those with TTM has revealed deficits in the same brain region (Stanley, Hannay, \& Breckenridge, 1997). Given the numerous similarities between barbering and TTM, further research on the etiology of treatment of barbering may benefit models of TTM in humans.

\section{Biological Factors}

Genetics-A specific TTM gene has not been identified in humans, although genetic research in animals and humans has yielded results suggesting that TTM may have a genetic basis. Novak, Keuthen, Stewart, and Pauls (2009) recently compared TTM concordance rates in 24 monozygotic and 10 dizygotic twin pairs. Using DSM-IV-TR criteria, TTM 
concordance rates were significantly higher in monozygotic pairs $(38 \%)$ than in dizygotic pairs $(0 \%, p=0.047)$.

The search for a particular gene(s) involved in TTM has produced interesting findings. Compulsive grooming behaviors have been observed in some knockout mice, such as those deficient of the postsynaptic synapse-associated protein 90/postsynaptic density-95associated protein 3 (SAPAP3). Zuchner, Wedland, et al. (2009) resequenced SAPAP3 in unrelated individuals with TTM $(\mathrm{N}=77)$, TTM and OCD $(\mathrm{N}=44)$, and normal controls ( $\mathrm{N}$ $=48$ ). Heterozygous variants in SAPAP3 were found in $4.2 \%$ of those with TTM/OCD and in only $1.1 \%$ of controls, leading researchers to conclude that this genotype may increase susceptibility for OCD spectrum behaviors, including TTM. Mutations in the slit and trk like 1 (SLITRK1) gene, which has been implicated in other repetitive behavior disorders (Abelson et al., 2005), were examined in 44 TTM nuclear families by Zuchner, Cuccaro, et al. (2009). Rare variants in SLITRK1 were found in $4.5 \%$ of the sample, suggesting that this gene may play a role in some cases of TTM. Other possible genes that may contribute to TTM susceptibility include those associated with the encoding of components in the serotonergic and dopaminergic neurotransmitter pathways (e.g., T102T-genotype; Hemmings et al., 2006) and genes expressed in cortico-basal ganglia circuits (e.g., Hoxb8; Greer \& Capecchi, 2002).

Neuroanatomy and neurochemistry-Abnormal repetitive behaviors, including TTM, are thought to involve dysregulation of parallel, segregated cortico-striato-thalamocortical (CSTC) circuits (Graybiel \& Rauch, 2000; Mink, 2001). These circuits regulate the selection and sequencing of behavior and include a direct pathway that initiates movements and an indirect pathway responsible for motoric inhibition. Disinhibition of the indirect pathway is thought to be particularly important in the etiology of repetitive behavior disorders, and TTM in particular seems to be associated with altered function of the prefrontal corticostriatal loop (Stanley et al., 1997). Imaging research has revealed several neurostructural deficits in individuals with TTM, including increased grey matter densities in areas associated with habit learning, cognition, and affect regulation (e.g., left striatum, left amygdalo-hippocampal formation, multiple cortical regions; Chamberlain et al., 2008); reduced cerebellar volumes (Keuthen, Makris, et al., 2007); and reduced basal ganglia volumes (O'Sullivan et al., 1997).

Research has not linked a specific neurochemical deficit with pulling severity. Based on outcome research suggesting favorable response to pharmacotherapy, some researchers have hypothesized that pulling severity is related to dysregulations of the serotonergic, noradrenergic, and/or dopaminergic systems (e.g., Swedo et al., 1989; Winchel et al., 1992).

Hormones-As mentioned earlier, increased barbering behavior in animals has been observed in mice who are reproductively active, leading some to conclude that TTM symptoms may be impacted by hormonal changes (Garner et al., 2004). In a cross-sectional study of 1,471 women with TTM, Flessner et al. (2009) found that fluctuations in "focused" pulling coincided with typical ages of important hormonal and biological changes, such as pubertal onset and perimenopause. Despite these findings, little experimental research has examined the relationship between hormones and TTM. In one small study, Epperson, 
McDougle, and Price (1996) conducted a double-blind controlled study comparing the effects of intranasal oxytocin and saline placebo on TTM symptoms in two women. TTM symptoms did not change acutely or after 7 days; however, the intranasal adminstration may not have enabled the hormone to cross the blood-brain barrier, which may explain why the hormone did not affect repetitive behavior. Clearly, more research is needed to understand if and how hormonal changes impact pulling.

Neuro-Cognitive factors-The cortical-striatal pathways implicated in TTM appear to play a key role in the acquisition and retrieval of motor sequences (Graybiel, 1998). Thus, hair pulling may be conceptualized as involving difficulties inhibiting abnormal repetitive action repertoires that are driven by tension or urges (i.e., response inhibition) and engaging in novel tasks which compete with the repetitive action repertoires (i.e., cognitive flexibility).

To examine whether TTM is characterized by difficulties with response inhibition, 17 individuals with TTM were compared to 20 healthy controls and 20 individuals with OCD on a Stop-Signal task. Those with TTM exhibited greater response inhibition deficits than either the OCD or healthy control group, and the degree of inhibitory deficit was moderately correlated with pulling severity (Chamberlain, Fineberg, Blackwell, Robbins, \& Sahakian, 2006). In another study, 21 individuals with TTM were compared to 17 normal controls on a Stroop test (Stanley et al., 1997). The TTM group again demonstrated deficient performance in comparison to the control group.

Deficits in cognitive flexibility have also been observed in persons with TTM. In one study, 23 individuals with TTM were compared to 21 individuals with OCD and 26 healthy controls on the Object Alternation Task (Bohne et al., 2005). Those with TTM showed a greater number of perseverative errors when compared to the healthy controls, suggesting greater difficulties in changing response patterns. Similarly, Stanley et al. (1997) demonstrated that adults with TTM performed worse on the Trails B test than normal controls, suggesting impaired cognitive flexibility in persons with TTM. In contrast, other studies demonstrated that those with TTM were no different than healthy control participants on a measure of cognitive flexibility (Intradimensional-Extradimensional Shift Task Score; Chamberlain, Blackwell, et al., 2006; Chamberlain, Fineberg, et al., 2006). Although data on flexibility are still contradictory, evidence for impaired flexibility in persons with TTM is consistent with a problematic habitual motor pattern of behavior.

Behavioral factors-Behavioral theories of TTM focus on the role of conditioning in pulling etiology and maintenance. Azrin and Nunn (1973) proposed that pulling may initially develop as a stress-coping behavior reinforced by tension-reduction. The notion that pulling may be maintained by negative reinforcement via reduction of aversive private experiences (i.e., not just tension or anxiety) has since garnered more support. In an examination of the affective states associated with pulling, Diefenbach et al. (2002) found that negative emotions such as tension, anxiety, boredom, and sadness may immediately precede pulling. Temporary reductions in these emotions were reported immediately following pulling. However, a later increase in unpleasant emotions such as guilt, anger, and sadness was observed, suggesting that emotional reactions to pulling may also set the 
occasion for future pulling episodes. In another study, Diefenbach et al. (2008) compared the emotional experience of hair pulling in individuals with TTM to nonclinical controls. At the onset of the pulling, the TTM group reported larger decreases in boredom, sadness, tension, and anger and larger increases in relief and calm. The TTM group also reported higher pleasure during pulling and greater guilt, sadness, and anger following pulling. These results further support the negative reinforcement model.

Pulling may also be maintained by positive reinforcement (Rapp et al., 1999). Positive reinforcers for pulling may include emotions of gratification, pleasure, or satisfaction experienced as a consequence of pulling; visual stimulation produced by particular hairs (e.g., plump roots; hairs of a particular thickness, texture, or color); and tactile stimulation created by prepulling hair twisting or stroking, pulling hairs out (e.g., sensation of popping), or post-pulling manipulations (e.g., rubbing hairs against body, face, lips; running hair between fingers).

Pulling "triggers," internal and external cues that increase the likelihood of pulling, may acquire their function via classical and operant conditioning processes (Diefenbach et al., 2000). Over time, the urge and/or pulling behaviors may become associated with many stimuli, such as specific settings, times of day, locations, or particular objects, which increases the likelihood that pulling will occur in the presence of those stimuli.

Emotional regulation-As described above, research has demonstrated reductions in aversive emotions following pulling (Diefenbach et al., 2002), supporting the notion that pulling may function as an emotion regulation strategy. There is also growing evidence to show that the relationship between specific emotional states and TTM severity may be moderated by an individual's history of escaping or avoiding unpleasant emotions or cognitions. This response tendency, termed experiential avoidance (Hayes, Wilson, Gifford, Follette, \& Strosahl, 1996), may be particularly important in the analysis of TTM. Begotka, Woods, and Wetterneck (2004) first demonstrated a significant relationship between pulling severity (as measured by the MGH-HS), and experiential avoidance (as measured by the Acceptance and Action Questionnaire; AAQ; Hayes et al., 2004). Experiential avoidance has also been shown to significantly moderate the relationship between hair-pulling severity and negative cognitions, including dysfunctional beliefs about appearance, fears of negative evaluation, and shameful cognitions (Norberg et al., 2007).

\section{Treatment of TTM}

The treatment of TTM has taken a circuitous path. The development of such treatments has historically proceeded in the absence of information on the basic psychopathology of the disorder. Despite this, effective treatments for TTM do exist. Studies demonstrating treatment efficacy have been reported with pharmacological and nonpharmacological interventions, and the vast majority of this research has been conducted with adults. Research from randomized controlled trials on the efficacy of pharmacotherapy in children and adolescents does not exist, and research on the effectiveness of behavioral procedures is very limited (e.g., Tolin, Franklin, Diefenbach, Anderson \& Meunier, 2007). Because the thrust of this paper is on psychological intervention and because the data on TTM treatment 
in children are so limited, we only provide a brief review research on pharmacotherapy, followed by a more extensive discussion on the development and outcome data for nonpharmacological interventions in adults.

\section{Medication Therapy}

Research on medication therapy for TTM has been mixed, with no one drug having been demonstrated efficacious in replicated randomized controlled trials. Of the medications that have been tested, two types predominate. Selective serotonin reuptake inhibitors (SSRIs), including fluoxetine and sertraline have been tested extensively in both crossover and randomized placebo controlled designs. Results have generally failed to demonstrate benefits of SSRIs over placebo (Christenson, Mackenzie, Mitchell, et al., 1991; Streichenwein \& Thornby, 1995) or wait list (van Minnen, Hoogduin, Keijsers, Hellenbrand, $\&$ Hendriks, 2003), perhaps raising concerns about the validity of neurochemical theories on the etiology of TTM. Clomipramine has also been tested, with mixed results. One of the first pharmacotherapy treatment studies in TTM compared clomipramine to desiprimine and showed superiority for clomipramine (Swedo et al., 1989). However, a more recent comparision between clomipramine, placebo, and behavior therapy failed to show separation between clomipramine and placebo (Ninan, Rothbaum, Martsteller, Knight, \& Eccard, 2000). In a recent meta analysis of medication studies for TTM, Bloch et al. (2007) noted that clomipramine was likely effective for TTM, whereas SSRIs were not. In the most recent controlled pharmacological treatment study of TTM, Grant, Odlaug and Kim (2009) compared pill placebo to N-Acytlcysteine, a glutamate modulator in 50 adults with TTM. Using a double-blind randomized trial design, results clearly showed that following 12 weeks of treatment, $\mathrm{N}$-Acytlcysteine yielded significantly greater reduction in pulling severity than placebo. Overall, $56 \%$ of the active group were considered treatment responders compared to $16 \%$ of the placebo condition. This finding is novel and promising, but awaits replication by an independent research group.

\section{Behavior Therapy for TTM}

Recent surveys of practitioners and persons with TTM suggest the most common form of nonpharmacological treatment for TTM involves one of many psychotherapies that have not been empirically tested (e.g., supportive therapy, hypnosis, psychoanalysis, or EMDR; Marcks, Wetterneck, \& Woods, 2006; Woods, Flessner, et al., 2006). Behavior therapy, another nonpharmacological approach with more empirical support, has also been used. Although a variety of behavioral procedures have been attempted as treatments for TTM (Altman, Haavik, \& Cook, 1978; Rapp, Miltenberger, Long, Elliott, \& Lumley, 1998), only one behavioral treatment, habit reversal therapy (HRT) has been studied in a rigorous fashion. Despite promising results, HRT's utility as a durable and stand-alone treatment for TTM is questionable.

Brief Description of HRT_HRT has been used to treat TTM and a host of other neuropsychiatric conditions including Tourette Disorder (e.g., Woods, Twohig, Flessner, \& Roloff, 2003), nail biting (e.g., Twohig, Woods, Marcks \& Teng, 2003), and self-injurious skin picking (e.g., Teng, Woods, \& Twohig, 2006). HRT combines awareness training (AT), competing response training (CRT), and social support (SS). AT involves increasing the 
participant's awareness of specific pulling episodes and the cognitive/emotional phenomena that precede pulling (e.g., specific situations, cognitions, or urges). In CRT, the participant is taught to engage in a "competing response" that is physically incompatible with the pulling. Participants are instructed to do the competing response (i.e., making a fist) for one minute contingent on the specific pulling behavior or on an occurrence of the preceding cognitive/ emotional phenomena. Social support involves the recruitment of a significant other in the participant's life who is instructed to prompt the participant to use the competing response when necessary and to praise him or her when the competing response is implemented correctly. In addition to AT, CRT, and SS, HRT often includes a "stimulus control" component. Stimulus control (SC) refers to specific strategies that can be implemented to reduce the likelihood that pulling will occur. For example, if tweezers are used to pull hair in front of a mirror, the participant may be asked to remove tweezers from the home and cover the mirror. Examples of SC techniques are endless, but primarily involve a direct individualized modification of the environment to reduce the likelihood of pulling.

Data on the Efficacy of HRT for TTM-A number of uncontrolled case studies (Rosenbaum \& Ayllon, 1981), controlled single-subject designs (e.g., Rapp et al., 1998; Tarnowski, Rosen, McGrath, \& Drabman, 1987), and uncontrolled group designs (Lerner, Franklin, Meadows, Hembree \& Foa, 1998; Mouton \& Stanley, 1996) provide preliminary support for the efficacy of HRT for TTM, but lack of experimentally controlled group designs weakens these claims.

Only three RCTs have been conducted to evaluate the efficacy of HRT for TTM, all of which involved adult samples of limited size. Azrin and colleagues found that HRT was more effective than another behavioral approach, negative practice, but the study was limited by exclusive reliance on patient self-report and substantial attrition (7 of 19) during the follow-up phase (Azrin, Nunn \& Frantz, 1980). In a second RCT, 23 persons with TTM were randomly assigned to one of three conditions: HRT+cognitive therapy (HRT/CT), clomipramine (CMI), or placebo (PBO). Treatment efficacy was measured via clinician ratings. Results showed that HRT/CT was more effective than the PBO or CMI conditions (Ninan et al., 2000). Specifically, HRT/CT showed an $89.7 \%$ decrease in pulling at posttreatment compared to a $38 \%$ decrease for CMI and a $10 \%$ decrease for PBO. These data are promising, but limited by the fact that initial sample sizes were very small ( $\mathrm{n}=6-10$ per group), the dropout rate high (40\% for CMI, 29\% for HRT/CT, and 17\% for PBO), and the follow-up assessment inadequate. The third, and perhaps most-well designed study involved 43 persons (16 years and older) who were randomly assigned to either wait-list ( $\mathrm{N}=15)$, FLU ( $\mathrm{N}=13$ ) or behavior therapy ( $\mathrm{N}=15$; van Minnen et al., 2003). Individuals assigned to the wait-list condition did not receive treatment for 12 weeks. Those assigned to the fluoxetine condition had their dosage titrated to $60 \mathrm{mg} / \mathrm{day}$, and those assigned to behavior therapy received SC and HRT procedures across 6 sessions held every other week. Drop-out rates were relatively low, with a $6 \%$ dropout rate for behavior therapy, $15 \%$ rate for FLU, and $0 \%$ for wait-list. Results showed that the behavior therapy procedures produced a significantly greater reduction in MGH-HS scores when compared to the waitlist and FLU groups at posttreatment. However, when using the independent hair damage ratings as the dependent variable, effect sizes were considerably smaller, and no longer 
significant. The Beck Depression Inventory (Beck, Steer, \& Brown, 1996) and Symptom Checklist-90 (SCL-90; Derogatis, Lipman \& Covi, 1973) were also administered at pre and post-treatment, but the groups did not differentially improve on these measures. A later study by the same research group looked at a 2 year follow-up of the behavioral treatment (Keijsers et al., 2006). Results showed a 70\% reduction in effect size from posttreatment to the 2 year follow-up.

Across all trials examining behavior therapy for TTM, findings suggest that behavior therapy may be useful for treating TTM. However, problems remain with the existing literature. First, there is a significant lack of a well-designed large-scale RCT with psychometrically sound assessment strategies administered by a blinded independent evaluator. Second, there has been a lack of follow-up assessment or unacceptable recurrence of symptoms. Finally, the treatments that have been tested have not been developed on a model of TTM etiology and maintenance that is grounded in empirically supported theory. From a blind efficacy perspective this latter criticism may be unimportant, but the development of a treatment based on an empirically-derived theoretical account not only provides an opportunity to advance knowledge about therapeutics for a particular problem, but also provides the opportunity to advance knowledge about the psychopathology of the disorder (Foa \& Kozak, 1997).

\section{Building Behavior Therapy for TTM from the Ground Up}

To move beyond the limitations of HRT, Mansueto and colleagues (1997) first acknowledged the need for a more comprehensive model of TTM to guide treatment development. As suggested by Mansueto, to develop a therapeutic procedure, it would be useful to utilize existing literature on the phenomenology of TTM, make informed decisions about how these factors may contribute to symptom expression, and combine into one integrated treatment package those treatment components that either have been found, or are believed to impact these specific factors.

Important Factors to Consider in the Treatment of TTM-In the development of a comprehensive treatment for TTM, it is important to recognize a number of factors that contribute to symptom severity and overall life impairment. By systematically combining treatment strategies designed to address these factors, a comprehensive and integrated treatment for TTM may be designed. Below, these factors are described and the steps taken in the creation of a comprehensive and integrated treatment are presented.

1. Idiosyncratic Factors in the Maintenance of Pulling. As described earlier, TTM can be evoked and reinforced by a host of different environmental stimuli. To address this factor, it would be helpful to systematically identify evocative and reinforcing stimuli for a client and create a particular set of therapeutic recommendations with the goal of reducing or eliminating these stimuli from the client's environment. This is typically what is done in the therapeutic technique for TTM known as stimulus control.

2. Feelings of Isolation, Embarrassment. One of the primary distressing symptoms experienced by those with TTM involves feelings of social isolation and a lack of 
understanding about their disorder (Wetterneck et al., 2006). The impact of these events is unknown, but it is plausible that these factors contribute to anxiety and depressive symptoms, and thus possibly an increase in TTM pulling severity. To counter this particular factor, psychoeducation about TTM may be useful in reducing feelings of isolation and improve one's sense of control over the disorder as it has with chronic pain (Lefort, Grey-Donald, Rowat, \& Jeans, 1998) and bodyimage issues (Cash \& Hrabosky, 2003). Although psychoeducation may provide some benefit, it is expected that education alone would be insufficient to produce substantial and maintainable gains in pulling severity.

3. Training Response Inhibition and Cognitive Flexibility: Individuals with TTM appear to have difficulties preventing, and once initiated, stopping or changing unwanted or inappropriate motor patterns (i.e., flexibility and inhibition). To address this deficit, it may be useful to specifically train the inhibition and disruption of the pulling. Although the mechanism of HRT is unclear (Miltenberger, Fuqua \& Woods, 1998), the treatment is designed to teach the individual to become aware of antecedents to pulling, engage in an alternative response to pulling when those antecedents are present or when pulling starts, and to reinforce this behavior.

4. Focused Pulling. More recent research has suggested an emotional/cognitive regulation function served by some episodes of pulling. Unfortunately, traditional behavior therapy does not appear to address the emotional or cognitive factors that may contribute to this function of pulling (van Minnen et al., 2003). To address this issue, various treatment components may be useful. For example, cognitive therapy procedures (e.g., cognitive restructuring, thought stopping) have been used to reduce emotional or cognitive factors, and dialectical behavior therapy strategies have been used with other psychiatric disorders to teach emotional regulation skills (Linehan, 1993). Another therapeutic strategy, based on principles of acceptance and commitment therapy have also begun to be employed in the treatment of a variety of different disorders including OCD (Twohig, Hayes \& Masuda, 2006a), skin picking (Twohig, Hayes \& Masuda, 2006b), and psychotic behavior (Bach \& Hayes, 2002), as well as food cravings (Forman et al., 2007). Given that TTM severity has been linked to experiential avoidance (the process specifically targeted in acceptance-based therapies), we believe it may be particularly useful to utilize an acceptance based treatment to address pulling episodes potentially impacted by experiential avoidance.

Summary of the Integration-Given this background work, our lab has combined the four aforementioned elements of treatment into an integrated treatment package for TTM, termed acceptance-enhanced behavior therapy for trichotillomania (AEBT-T). Although the HRT, stimulus control, and psychoeducation components (described above) are relatively common elements to traditional behavior therapy for TTM, the integration of Acceptance and Commitment Therapy (ACT; Hayes, Strosahl, \& Wilson, 1999) is novel, and thus worth a brief description. 
Acceptance and Commitment Therapy (ACT) is a therapeutic approach designed to (1) promote the rejection of emotional control strategies that interfere with working toward valued life goals, (2) increase one's willingness to accept the occurrence of private experiences such as urges, thoughts, feelings, or cravings, (3) create defusion from the literal meaning of language, (4) encourage the participant to experience the discomfort created by unpleasant private experiences while behaving in a way that is consistent with one's valued life direction, and (5) encourage participants to refrain from behaviors with pleasurable consequences if that behavior disrupts one's progression toward one's valued goals (Hayes, Strosahl, et al., 1999). ACT was derived from basic experimental research on human language and cognition (Relational Frame Theory; Hayes, Barnes-Holmes \& Roche, 2001). The overarching goal of ACT is to alter the context of human language from one that accepts private events as causes for behavior to one that promotes the experience of having private events (pleasant or unpleasant) while moving in a valued life direction. Although a comprehensive description of the procedure is not possible here, ACT achieves this goal through the use of experiential exercises and metaphors. Specific attempts to alter or change the content of thoughts or emotions are avoided. It is believed that by changing the context of language surrounding private events, one may continue to experience unpleasant urges, thoughts, emotions, or cravings but that such events will no longer have an impact on psychological well-being or overt behavior.

As evidence accrues on the efficacy of acceptance-based interventions for various problems, data are beginning to demonstrate clearly that ACT decreases experiential avoidance. For example, studies on pain tolerance have shown that an acceptance-based intervention results in significantly greater pain tolerance in a cold-pressor task when compared to various control conditions (Guitierrez, Luciano \& Fink, 2004; Hayes, Bissett, et al., 1999). Additional support showing that acceptance based interventions decrease experiential avoidance come from a study by Levitt, Brown, Orsillo, and Barlow (2004). In this study, participants with panic disorder listened to either a brief acceptance rationale, suppression rationale, or neutral narrative prior to undergoing a carbon dioxide challenge, which consisted of exposure to $5.5 \% \mathrm{CO}_{2}$ enriched air for 15 minutes. Subjective ratings of anxiety during the task did not differ between groups; however, those in the acceptance group did not evaluate the anxiety as negatively as did those in the other groups and were more willing to participate in an additional challenge. Finally, in two studies specific to TTM, results showed that experiential avoidance decreased significantly from pre-post treatment following a course of ACT and HRT, and that this decrease was strongly correlated with reductions in pulling (Marcks et al., 2006; Woods, Wetterneck, \& Flessner, 2006).

Developing a Treatment for TTM-Based on these theoretical considerations, our group crafted an initial treatment manual, which was evaluated and revised in a systematic process. To date we have conducted a feasibility trial, which resulted in a revision of the original manual. This revised manual was then tested in a small randomized controlled pilot study and subsequently further revised. Currently, we are conducting a large RCT comparing AEBT-T to a psychoeducation/supportive therapy condition (PI: Woods; R01MH080966). Below, we outline the results and manual modifications stemming from the feasibility and pilot trials. 
Feasibility Study of AEBT-T_In the initial feasibility trial (Twohig \& Woods, 2004), a 7 -session treatment manual was implemented with 6 adult participants, utilizing two separate multiple baseline across subjects designs. The first four sessions involved ACT components, and the final three sessions were dedicated to HRT and SC. The dependent variable was self-report of hairs pulled per day, collected and reported daily to the experimenters. Pre- and post photographs of the affected area were also collected and scored by independent evaluators.

Sessions occurred weekly: The first five sessions were one hour in duration and the final two each lasted $30 \mathrm{~min}$. The therapists had been trained in ACT by Steven Hayes, and both therapists had extensive experience in implementing HRT. During the four ACT-focused sessions, treatment centered on (a) abandoning strategies used to control urges to pull, thoughts, emotions, or other aversive private experiences, (b) acceptance of, or willingness to experience one's private events, (c) defusion from the literal meaning of language, and (d) heading in a valued life direction. HRT and SC was implemented in the fifth session and reviewed in sessions 6 and 7, which occurred during the three weeks following the ACTonly sessions.

Data were interpreted using visual inspection procedures: The intervention produced pre-post decreases in hair pulling to zero levels for four of the six participants. Results were maintained for three of the four at follow-up. Moderate decreases were seen in the pulling of the remaining two participants. MGH-HS scores collected at pretreatment, posttreatment, and follow-up showed a $63 \%$ reduction at posttreatment, with gains maintained at the 3 mo follow-up. Independent photograph ratings confirmed the self-report findings. All participants evaluated the treatment positively.

Modification of the Original AEBT-T Protocol-The initial 7-session protocol demonstrated promising results. Nevertheless, based on therapist experiences and feedback from the participants, the treatment was modified in four ways: (a) the number of sessions was increased from 7 to 10 to provide more time for ACT content, as therapists and participants reported feeling rushed on the ACT material; (b) the values component of ACT was placed at the beginning of treatment to allow the participant to be working toward a clear and valued goal; (c) some of the metaphors used during the initial pilot test were not well-received and dropped in the revised manual; and (d) relapse prevention techniques were added into the final two sessions to improve the maintenance of the treatment gains.

\section{Initial Controlled Pilot Study Comparing AEBT-T to Wait-List Control (WL) -} The modified manual was tested in a small RCT funded by the Trichotillomania Learning Center (a national patient support organization; Woods, Wetterneck, et al., 2006). Twentyeight participants were randomly assigned to one of the two conditions (14 AEBT-T, and 14 WL control). Two from the AEBT-T and one from the WL condition dropped out for reasons unrelated to the study. A blinded IE evaluated the participants at pretreatment and post-treatment. At the end of the posttreatment assessment, the WL participants were offered AEBT-T and reassessed at the end of treatment. All individuals in the initial AEBT-T condition were re-assessed at a 3 -month follow-up. In addition to assessing pulling severity 
with self report (MGH-Hairpulling Scale) and IE rating (NIMH-TIS Rating), depression and anxiety measures were taken, as was a measure of experiential avoidance at all points.

Results showed that pulling severity across both indices decreased for the AEBT-T group, but not for the WL group (Between Group Differences: $\mathrm{d}_{\mathrm{MGH}}=1.71$, $\mathrm{d}_{\text {NIMH-Impairment }}=1.38$ ). Likewise, after the WL group received treatment, they also showed significant decreases in all indicators of pulling severity. Overall, $66 \%$ of treatment recipients were deemed "treatment responders," and these results maintained at the 3-month follow-up. In addition, significant reductions were seen for the AEBT-T group in measures of anxiety and depression, but these decreases were not seen in the WL group.

Additional analyses investigating potential mechanisms of change indicated that pre-post decreases in the measure of the experiential avoidance (as measured by the AAQ) were moderately and significantly correlated with pre-post decreases in MGH-HS scores ( $r=.59)$. Treatment compliance ratings completed by both clinician and participant were also positively and significantly correlated with reduction of symptoms at posttreatment $(\mathrm{r}=.57-$. 67).

At the end of the pilot study, participants also rated the perceived utility of each treatment component on a 1-5 scale, with 1 being not at all useful and 5 being extremely useful. No specific claims can be made about the actual contribution of each component to symptom improvement, but the data on perceived utility suggested that greater emphasis should be placed on particular treatment components over others. The HRT components of awareness training and competing response training, along with stimulus control techniques were perceived as very useful, Social support was perceived to be of little utility. In terms of ACT components, extensive work on clarifying participant values was not perceived as particularly useful relative to other ACT components. Based on these and other data, the manual tested in this RCT was further revised. The primary revisions included (1) introducing HRT and stimulus control techniques earlier in therapy, (2) de-emphasizing the values work while increasing the focus on control, willingness, and defusion, (3) further trying to integrate the ACT and HRT components by encouraging the use of specific ACT defusion and willingness components during HRT implementation, and (4) removing the formal social support component from the treatment manual. The revised manual that was published (Woods \& Twohig, 2008) and is being tested in the aforementioned federally funded study.

\section{Preliminary Evidence for the Independent Contributions of ACT and HRT-}

Given the structure of AEBT-T and the absence of dismantling studies, it is difficult to ascertain the separate and unique impact of the ACT and HRT interventions. Nevertheless, three streams of preliminary evidence suggest that both interventions are likely to have an independent effect on TTM. First, in the feasibility study, the implementation of ACT alone reduced pulling to near-zero levels with no additional decreases seen following HRT for three participants. One participant, however, showed a slight impact following ACT, but more substantial change with the addition of HRT. Second, in the AEBT-T pilot study, session by session MGH-HS data showed that $45 \%$ of the observed reduction in the MGHHS scores occurred between sessions 1 and 8 , which corresponded to the implementation of 
ACT. The remaining percentage of symptom reduction took place following Session 9, which corresponded to HRT+stimulus control components. Third, in a recently completed multiple-baseline pilot study (Flessner, Busch, Heideman \& Woods, 2008), two individuals with TTM received 7 sessions of ACT and then HRT was added, and one individual received HRT first, followed by the implementation of ACT. With all three participants, the greatest benefit did not occur until both treatment components had been implemented. Although such data are no substitution for a well-conducted dismantling study, existing evidence supports the idea that ACT and HRT may independently contribute to symptom reduction and suggests that the greatest benefit may be achieved from a combination of the two interventions.

\section{Summary}

Trichotillomania is a relatively prevalent and debilitating mental health condition that has received comparatively little attention from either behavioral or biological researchers. The availability of well-established interventions for the disorder in adults is limited, with only HRT-based behavior therapy and clomipramine appearing to be efficacious in replicated trials. Despite the support for these interventions, they are limited in their efficacy, maintenance and scope. Not all patients improve, many of those who improve do not stay improved, and preliminary results suggest that improvements may be limited to the pulling behavior itself and do not necessarily impact many of the problematic co-occurring symptoms such as anxiety and depression.

Given these limitations, researchers have begun to explore treatments tailored to a more nuanced understanding of the disorder. Multiple tailored approaches could be used. Modular approaches (i.e., Franklin \& Tolin, 2007; Mansueto et al., 1997) would attempt to match a patient's particular pulling profile with specific therapeutic techniques. Other strategies could employ standard-package behavior therapy techniques (i.e., HRT and SC) with treatment strategies (i.e., DBT, ACT) designed to address what traditional behavior therapy for TTM does not (i.e., emotional control function of pulling). Having identified at least two distinct styles of pulling often present in persons with TTM, we have developed an acceptance-based behavior therapy approach to treat adults with the disorder. As with traditional behavioral techniques, our treatment employs HRT and SC procedures to target "automatic pulling" and based on the research suggesting that experiential avoidance moderates the relationship between negative cognitions and pulling severity, we add acceptance and commitment therapy to aid in the treatment of "focused pulling." Preliminary research from our group suggests that this combined intervention is effective, the results maintained, and the two individual treatment components make independent contributions to improvement. Despite these results, there is clearly a need for more research, not only on ACT-enhanced behavior therapy for TTM, but on the disorder itself. It is only through a more thorough understanding by the biological and behavioral mechanisms underlying the disorder that we will be able to develop the most efficacious treatments.

\section{Acknowledgments}

This research was supported, in part, by a National Institute of Mental Health Grant MH080966 to Douglas W. Woods. 


\section{References}

Abelson JF, Kwan KY, O'Roak BJ, Baek DY, Stillman AA, Morgan TM, et al. Sequence variants in SLITRK1 are associated with Tourette's syndrome. Science. 2005; 310:317-320. [PubMed: 16224024]

Altman K, Haavik S, Cook JW. Punishment of self-injurious behavior in natural settings using contingent aromatic ammonia. Behaviour Research and Therapy. 1978; 16:85-96. [PubMed: 678273]

American Psychiatric Association. Diagnostic and statistical manual of mental disorders, fourth edition, text revision. Washington, DC: American Psychiatric Association; 2000.

Azrin NH, Nunn RG. Habit-reversal: A method of eliminating nervous habits and tics. Behaviour Research and Therapy. 1973; 11:619-628. [PubMed: 4777653]

Azrin NH, Nunn RG, Frantz SE. Treatment of hair pulling (trichotillomania): A comparative study of habit reversal and negative practice training. Journal of Behavior Therapy and Experimental Psychiatry. 1980; 25:189-196.

Bach P, Hayes SC. The use of acceptance and commitment therapy to prevent the rehospitalization of psychotic patients: A randomized controlled trial. Journal of Consulting and Clinical Psychology. 2002; 70:1129-1139. [PubMed: 12362963]

Beck, AT.; Steer, RA.; Brown, GK. Beck Depression Inventory Manual. 2. San Antonio, TX: Psychological Corporation; 1996.

Begotka AM, Woods DW, Wetterneck CT. The relationship between experiential avoidance and the severity of trichotillomania in a nonreferred sample. Journal of Behavior Therapy and Experimental Psychiatry. 2004; 35:17-24. [PubMed: 15157815]

Bloch MH, Landeros-Weisenberger A, Dombrowski P, Kelmendi B, Wegner R, Nudel J, et al. Systematic review: Pharmacological and behavioral treatment for trichotillomania. Biological Psychiatry. 2007; 62:839-846. [PubMed: 17727824]

Bohne A, Savage CR, Deckersbach T, Keuthen NJ, Jenike MA, Tuschen-Caffier B, Wilhelm S. Visuospatial abilities, memory, and executive functioning in trichotillomania and obsessivecompulsive disorder. Journal of Clinical and Experimental Neuropsychology. 2005; 27:385-399. [PubMed: 15962686]

Bouwer C, Stein DJ. Trichobezoars in trichotillomania: case report and literature overview. Psychosomatic Medicine. 1998; 60:658-660. [PubMed: 9773774]

Casati J, Toner BB, Yu B. Psychosocial issues for women with Trichotillomania. Comprehensive Psychiatry. 2000; 41:344-351. [PubMed: 11011830]

Cash TF, Hrabosky JI. The effects of psychoeducation and self-monitoring in a cognitive-behavioral program for body-image improvement. Eating Disorders: The Journal of Treatment \& Prevention. 2003; 11:255-270.

Chamberlain SR, Blackwell AD, Fineberg NA, Robbins TW, Sahakian BJ. Strategy implementation in obsessive-compulsive disorder and trichotillomania. Psychological Medicine. 2006; 36:91-97. [PubMed: 16202188]

Chamberlain SR, Fineberg NA, Blackwell AD, Robbins TW, Sahakian BJ. Motor inhibition and cognitive flexibility in obsessive-compulsive disorder and trichotillomania. American Journal of Psychiatry. 2006; 163:1282-1284. [PubMed: 16816237]

Chamberlain SR, Menzies LA, Fineberg NA, Del Campo N, Suckling J, Craig K, et al. Grey matter abnormalities in trichotillomania: Morphometric magnetic resonance imaging study. British Journal of Psychiatry. 2008; 193:216-221. [PubMed: 18757980]

Christenson GA, Mackenzie TB, Mitchell JE. Characteristics of 60 adult chronic hair pullers. American Journal of Psychiatry. 1991; 148:365-370. [PubMed: 1992841]

Christenson GA, Mackenzie TB, Mitchell JE, et al. A placebo-controlled double-blind crossover study of fluoxetine in trichotillomania. American Journal of Psychiatry. 1991; 148:1566-1571. [PubMed: 1928474]

Christenson, GA.; Manuseuto, CS. Trichotillomania: descriptive characteristics and phenomenology. In: Stein, DJ.; Christenson, GA.; Hollander, E., editors. Trichotillomania. Washington, DC: American Psychiatric Press; 1999. p. 1-41. 
Christenson GA, Pyle RL, Mitchell JE. Estimated lifetime prevalence of trichotillomania in college students. Journal of Clinical Psychiatry. 1991; 52:415-417. [PubMed: 1938977]

Christenson GA, Ristvedt SL, Mackenzie TB. Identification of trichotillomania cue profiles. Behaviour Research and Therapy. 1993; 31:315-320. [PubMed: 8476406]

Cohen LJ, Stein DJ, Simeon D, Spadaccini E. Clinical profile, comorbidity, and treatment history in 123 hair pullers: A survey study. Journal of Clinical Psychiatry. 1995; 56:319-326. [PubMed: 7615485]

Derogatis LR, Lipman RS, Covi L. SCL-90: An outpatient psychiatric rating scale - preliminary report. Psychopharmacology Bulletin. 1973; 9:13-28. [PubMed: 4682398]

Diefenbach GJ, Mouton-Odum S, Stanley MA. Affective correlates of trichotillomania. Behaviour Research and Therapy. 2002; 40:1305-1315. [PubMed: 12384325]

Diefenbach GJ, Reitman D, Williamson DA. Trichotillomania: A challenge to research and practice. Clinical Psychology Review. 2000; 20:289-309. [PubMed: 10779896]

Diefenbach GJ, Tolin DF, Crocetto JS, Maltby N, Hannan SE. Assessment of trichotillomania: a psychometric evaluation of hair pulling scales. Journal of Psychopathology and Behavioral Assessment. 2005; 27:169-178.

Diefenbach GJ, Tolin DF, Hannan S, Crocetto J, Worhunsky P. Trichotillomania: Impact on psychosocial functioning and quality of life. Behavior Research and Therapy. 2006; 43:869-884.

Diefenbach GJ, Tolin DF, Meunier S, Worhunsky P. Emotion regulation and trichotillomania: A comparison of clinical and nonclinical hair pulling. Journal of Behavior Therapy and Experimental Psychiatry. 2008; 39:32-41. [PubMed: 17207769]

Dufour, BD.; Garner, JP. An ethological analysis of barbering behavior. In: Kalueff, A.; Bergner, C.; LaPorte, J., editors. Neurobiology of Grooming Behavior. Cambridge, UK: Cambridge University Press; in press

du Toit PL, van Kradenburg J, Niehaus DJH, Stein DJ. Characteristics and phenomenology of hair pulling: An exploration of subtypes. Comprehensive Psychiatry. 2001; 42:247-256. [PubMed: 11349246]

Epperson CN, McDougle CJ, Price LH. Intranasal oxytocin in obsessive-compulsive disorder. Biological Psychiatry. 1996; 40:547-549. [PubMed: 8879477]

Flessner CA, Busch AM, Heideman PW, Woods DW. Acceptance-enhanced behavior therapy (AEBT) for trichotillomania and chronic skin picking: Exploring the effects of component sequencing. Behavior Modification. 2008; 32:579-594. [PubMed: 18334614]

Flessner CA, Woods DW, Franklin ME, Cashin SE, Keuthen NJ. Trichotillomania Learning Center Scientific Advisory Board. The Milwaukee inventory for subtypes of trichotillomania-adult version (MIST-A): development of an instrument for the assessment of "focused" and "automatic" hairpulling. Journal of Psychopathology and Behavioral Assessment. 2008; 30:20-30.

Flessner CA, Woods DW, Franklin ME, Keuthen NJ, Piacentini J. Cross-sectional study of women with trichotillomania: A preliminary examination of pulling styles, severity, phenomenology, and functional impact. Child Psychiatry and Human Development. 2009; 40:153-167. [PubMed: 18780180]

Flessner CA, Woods DW, Franklin ME, Keuthen NJ, Piacentini J, Cashin SE, et al. The Milwaukee inventory for styles of trichotillomania-child version (MIST-C): initial development and psychometric properties. Behavior Modification. 2007; 31:896-918. [PubMed: 17932243]

Foa EB, Kozak MJ. Beyond the efficacy ceiling? Cognitive behavior therapy in search of theory. Behavior Therapy. 1997; 28:601-611.

Forman EM, Hoffman KL, McGrath KB, Herbert JD, Brandsma LL, Lowe MR. A comparison of acceptance- and control-based strategies for coping with food cravings: An analog study. Behaviour Research and Therapy. 2007; 45:2372-2386. [PubMed: 17544361]

Franklin ME, Flessner CA, Woods DW, Keuthen NJ, Piacentini JC, Moore P, et al. The child and adolescent trichotillomania impact project: Descriptive psychopathology, comorbidity, functional impairment, and treatment utilization. Journal of Developmental and Behavioral Pediatrics. 2008; 29:493-500. [PubMed: 18955898]

Franklin, ME.; Tolin, D. Treating trichotillomania: Cognitive-behavioral therapy for hairpulling and related problems. New York, NY: Springer Press; 2007. 
Garner JP, Meehan CL, Famula TR, Mench JA. Genetic, environmental, and neighbor effects on the severity of stereotypies and feather picking in Orange-winged Amazon parrots (amazona amazonica): An epidemiological study. Applied Animal Behaviour Science. 2006; 96:153-168.

Garner JP, Weisker SM, Dufour B, Mench JA. Barbering (fur and whisker trimming) by laboratory mice as a model of human trichotillomania and obsessive-compulsive spectrum disorders. Comparative Medicine. 2004; 54:216-224. [PubMed: 15134369]

Grant JE, Odlaug BL, Kim SW. N-Acetylcysteine, a glutamate modulator, in the treatment of trichotillomania: A double-blind, placebo-controlled study. Archives of General Psychiatry. 2009; 66:756-763. [PubMed: 19581567]

Grant JE, Odlaug BL, Potenza MN. Addicted to hair pulling? How an alternate model of trichotillomania may improve treatment outcome. Harvard Review of Psychiatry. 2007; 15:80-85. [PubMed: 17454177]

Graybiel AM. The basal ganglia and chunking of action repertoires. Neurobiology of Learning and Memory. 1998; 70:119-136. [PubMed: 9753592]

Graybiel AM, Rauch SL. Toward a neurobiology of obsessive-compulsive disorder. Neuron. 2000; 28:343-347. [PubMed: 11144344]

Greer JM, Capecchi MR. Hoxb8 is required for normal grooming behavior in mice. Neuron. 2002; 33:23-34. [PubMed: 11779477]

Guitierrez O, Luciano C, Fink BC. Comparison between an acceptance-based and a cognitive-controlbased protocol for coping with pain. Behavior Therapy. 2004; 35:767-784.

Hanna GL. Trichotillomania and related disorders in children and adolescents. Child Psychiatry \& Human Development. 1997; 27:255-268. [PubMed: 9200885]

Hayes, SC.; Barnes-Holmes, D.; Roche, B., editors. Relational frame theory: A post-Skinnerian account of human language and cognition. New York: Kluwer Academic/Plenum Publishers; 2001.

Hayes SC, Bissett R, Korn Z, Zettle RD, Rosenfarb I, Cooper L, Grundt A. The impact of acceptance versus control rationales on pain tolerance. Psychological Record. 1999; 49:33-47.

Hayes SC, Bissett RT, Strosahl K, Wilson K, Pistorello J, Toarmina M, Polusny MA, Batten SV, Dykstra TA, Stewart SH, Zvolensky MJ, Eifert GH, Bergan J, Follette WC. Measuring experiential avoidance: A preliminary test of a working model. The Psychological Record. 2004; 54:553-578.

Hayes, SC.; Strosahl, KD.; Wilson, KG. Acceptance and Commitment Therapy: An Experiential Approach to Behavior Change. New York: The Guilford Press; 1999.

Hayes SC, Wilson KG, Gifford EV, Follette VM, Strosahl KD. Experiential avoidance and behavioral disorders: A functional dimensional approach to diagnosis and treatment. Journal of Consulting and Clinical Psychology. 1996; 64:1152-1168. [PubMed: 8991302]

Keijsers GPJ, van Minnen A, Hoogduin CAL, Klaassen BNW, Hendriks MJ, Tanis-Jacobs J. Behavioural treatment of trichotillomania: Two-year follow-up results. Behaviour Research and Therapy. 2006; 44:359-370. [PubMed: 15927144]

Keuthen NJ, Dougherty DD, Franklin ME, Bohne A, Loh R, Levy J, et al. Quality of life and functional impairment in individuals with trichotillomania. The Journal of Applied Research. 2004; 4:186-197.

Keuthen NJ, Flessner CA, Woods DW, Franklin ME, Stein DJ, Cashin SE, et al. Factor analysis of the Massachusetts General Hospital Hairpulling Scale. Journal of Psychosomatic Research. 2007; 62:707-709. [PubMed: 17540230]

Keuthen NJ, Makris N, Schlerf JE, Martis B, Savage CR, McMullin K, et al. Evidence for reduced cerebellar volumes in trichotillomania. Biological Psychiatry. 2007; 61:374-381. [PubMed: 16945351]

Keuthen NJ, O'Sullivan RL, Ricciardi JN, Shera D, Savage CR, Borgmann AS, et al. The Massachusetts General Hospital (MGH) Hairpulling Scale: I. Development and factor analyses. Psychotherapy and Psychosomatics. 1995; 64:141-145. [PubMed: 8657844]

King RA, Scahill L, Vitulano LA, Schwab-Stone M, Tercyak K, Riddle M. Childhood Trichotillomania: Clinical phenomenology, comorbidity, and family genetics. Journal of the 
American Academy of Child and Adolescent Psychiatry. 1995; 34:1451-1459. [PubMed: 8543512]

King RA, Zohar AH, Ratzoni G, Binder M, et al. An epidemiological study of trichotillomania in Israeli adolescents. Journal of the American Academy of Child \& Adolescent Psychiatry. 1995; 34:1212-1215. [PubMed: 7559316]

Lefort SM, Gray-Donald K, Rowat KM, Jeans ME. Randomized controlled trial of a community-based psychoeducation program for the self-management of chronic pain. Pain. 1998; 74:297-306. [PubMed: 9520244]

Lerner J, Franklin ME, Meadows EA, Hembree E, Foa E. Effectiveness of a cognitive behavioral treatment program for trichotillomania: An uncontrolled evaluation. Behavior Therapy. 1998; 29:157-171.

Levitt JT, Brown TA, Orsillo SM, Barlow DH. The effects of acceptance versus suppression of emotion on subjective and psychophysiological response to carbon dioxide challenge in patients with panic disorder. Behavior Therapy. 2004; 35:747-766.

Linehan, MM. Cognitive-behavioral treatment of borderline personality disorder. New York, NY: Guilford Press; 1993.

Mansueto CS, Townsley-Stemberger RM, McCombs-Thomas A, Goldfinger-Golomb R. Trichotillomania: A comprehensive behavioral model. Clinical Psychology Review. 1997; 17:567-577. [PubMed: 9260041]

Marcks BA, Wetterneck CT, Woods DW. Investigating healthcare providers' knowledge of trichotillomania and its treatment. Cognitive Behaviour Therapy. 2006; 35:19-27. [PubMed: 16562364]

McCarley NG, Spirrson CL, Ceminsky JL. Hair pulling behavior reported by African American and non-African American college students. Journal of Psychopathology and Behavioral Assessment. 2002; 24:139-144.

Miltenberger RG, Fuqua RW, Woods DW. Applying behavior analysis with clinical problems: Review and analysis of habit reversal. Journal of Applied Behavior Analysis. 1998; 31:447-469. [PubMed: 9757583]

Mink JW. Neurobiology of basal ganglia circuits in Tourette syndrome: Faulty inhibition of unwanted motor patterns? Advances in Neurology. 2001; 85:113-122. [PubMed: 11530421]

Mouton SG, Stanley MA. Habit reversal training for trichotillomania: A group approach. Cognitive and Behavioral Practice. 1996; 3:159-182.

Neal-Barnett A, Stadulis R. Affective correlates and racial identity in African-American women with trichotillomania. Journal of the National Medical Association. 2006; 98:753-757. [PubMed: 16749651]

Neal-Barnett AM, Ward-Brown BJ, Mitchell M, Krownapple M. Hairpulling in African Americansonly your hairdresser knows for sure: An exploratory study. Cultural Diversity \& Ethnic Minority Psychology. 2000; 6:352-362. [PubMed: 11089311]

Ninan PT, Rothbaum BO, Martsteller FA, Knight BT, Eccard MB. A placebo-controlled trial of cognitive behavioral therapy and clomipramine in trichotillomania. Journal of Clinical Psychiatry. 2000; 61:47-50. [PubMed: 10695646]

Norberg MM, Wetterneck CT, Woods DW, Conelea CA. Experiential avoidance as a mediator of relationships between cognitions and hair-pulling severity. Behavior Modification. 2007; 31:367381. [PubMed: 17548535]

Novak CE, Keuthen NJ, Stewart SE, Pauls DE. A twin concordance study of trichotillomania. American Journal of Medical Genetics Part B: Neuropsychatric Genetics. 2009; 150B:944-949.

O'Sullivan RL, Keuthen NJ, Hayday CF, Ricciardi JN, Buttolph ML, Jenike MA, et al. Massachusetts General Hospital (MGH) Hairpulling Scale: 2. Reliability and validity. Psychotherapy and Psychosomatics. 1995; 64:146-148. [PubMed: 8657845]

O'Sullivan RL, Rauch SL, Breiter HC, Grachev ID, Baer L, Kennedy DN, et al. Reduced basal ganglia volumes in trichotillomania measured via morphometric magnetic resonance imaging. Biological Psychiatry. 1997; 42:39-45. [PubMed: 9193740]

Rapp JT, Miltenberger RG, Galensky TL, Ellingson SA, Long ES. A functional analysis of hair pulling. Journal of Applied Behavior Analysis. 1999; 32:329-337. [PubMed: 10513028] 
Rapp JT, Miltenberger RG, Long ES, Elliott AJ, Lumley VA. Simplified habit reversal treatment for chronic hair pulling in three adolescents: A clinical replication with direct observation. Journal of Applied Behavior Analysis. 1998; 31:299-302. [PubMed: 9652106]

Reeve EA, Bernstein GA, Christenson GA. Clinical characteristics and psychiatric comorbidity in children with trichotillomania. Journal of the American Academy of Child \& Adolescent Psychiatry. 1992; 31:132-138. [PubMed: 1537764]

Rothbaum BO. The behavioral treatment of trichotillomania. Behavioral Psychotherapy. 1992; 20:8590.

Rothbaum BO, Ninan PT. The assessment of trichotillomania. Behavior Research and Therapy. 1994; 32:651-662.

Soriano JL, O’Sullivan RL, Baer L, Philips KA, McNally RJ, Jenike MA. Trichotillomania and selfesteem: A survey of 62 hair pullers. Journal of Clinical Psychiatry. 1996; 57:77-82. [PubMed: 8591973]

Stanley MA, Borden JW, Bell GE, Wagner AL. Nonclinical hair pulling: Phenomenology and related psychopathology. Journal of Anxiety Disorders. 1994; 8:119-130.

Stanley MA, Bowers TC, Swann AC, Taylor DJ. Treatment of trichotillomania with fluoxetine (letter). Journal of Clinical Psychiatry. 1991; 52:282. [PubMed: 2055906]

Stanley MA, Breckenridge JK, Snyder AG, Novy DM. Clinician rated measure of hairpulling: A preliminary psychometric evaluation. Journal of Psychopathology and Behavioral Assessment. 1999; 21:157-182.

Stanley MA, Hannay HJ, Breckenridge JK. The neuropsychology of trichotillomania. Journal of Anxiety Disorders. 1997; 11:473-488. [PubMed: 9407267]

Stein, DJ.; Christenson, GA.; Hollander, E. The Neurobiology of Trichotillomania. In: Stein, DJ.; Christenson, GA.; Hollander, E., editors. Trichotillomania. Washington, DC: American Psychiatric Press, Inc; 1999. p. 43-61.

Stein, DJ.; Lochner, C.; Hemmings, S.; Kinnear, C. Trichotillomania: An Obsessive-Compulsive Spectrum Disorder. In: Abramowitz, JS.; Houts, AC., editors. Concepts and controversies in obsessive-compulsive disorder. New York: Springer Science + Business Media; 2005. p. 151-161.

Stemberger RM, Thomas AM, Mansueto CS, Carter JG. Personal toll of trichotillomania: Behavioral and interpersonal sequelae. Journal of Anxiety Disorders. 2000; 14:97-104. [PubMed: 10770238]

Streichenwein SM, Thornby JI. A long-term, double-blind, placebo-controlled crossover trial of the efficacy of fluoxetine for trichotillomania. American Journal of Psychiatry. 1995; 152:1192-1196. [PubMed: 7625469]

Swedo SE, Leonard HL. Trichotillomania: an obsessive-compulsive spectrum disorder? Psychiatric Clinics of North America. 1992; 15:777-790. [PubMed: 1461795]

Swedo SE, Leonard HL, Rapoport JL, Lenane MC, Goldberger EL, Cheslow DL. A double-blind comparison of clomipramine and desipramine in the treatment of trichotillomania (hair pulling). New England Journal of Medicine. 1989; 321:497-501. [PubMed: 2761586]

Tarnowski KJ, Rosen LA, McGrath ML, Drabman RS. A modified habit reversal procedure in a recalcitrant case of trichotillomania. Journal of Behavior Therapy and Experimental Psychiatry. 1987; 18:157-163. [PubMed: 3611384]

Teng EJ, Woods DW, Twohig MP. Habit reversal as a treatment for chronic skin picking and its psychological correlates: Comparison to a wait-list control. Behavior Modification. 2006; 30:411422. [PubMed: 16723422]

Tolin DF, Diefenbach GJ, Flessner CA, Franklin ME, Keuthen NJ, Moore P, et al. The TTM scale for children: development and validation. Child Psychiatry and Human Development. 2008; 39:331349. [PubMed: 18183484]

Tolin DF, Franklin ME, Diefenbach GJ, Anderson E, Meunier SA. Pediatric trichotillomania: Descriptive psychopathology and an open trial of cognitive behavior therapy. Cognitive Behaviour Therapy. 2007; 36:129-144. [PubMed: 17852170]

Twohig MP, Hayes SC, Masuda A. Increasing willingness to experience obsessions: Acceptance and Commitment Therapy as a treatment for Obsessive Compulsive Disorder. Behavior Therapy. 2006a; 37:3-13. [PubMed: 16942956] 
Twohig MP, Hayes SC, Masuda A. A preliminary investigation of Acceptance and Commitment Therapy as a treatment for chronic skin picking. Behaviour Research and Therapy. 2006b; 44:1513-1522. [PubMed: 16368072]

Twohig MP, Woods DW. A Preliminary Investigation of Acceptance and Commitment Therapy and Habit Reversal as a Treatment for Trichotillomania. Behavior Therapy. 2004; 35:803-820.

Twohig MP, Woods DW, Marcks BA, Teng EJ. Evaluating the efficacy of habit reversal: Comparison to a placebo control. Journal of Clinical Psychiatry. 2003; 64:40-48. [PubMed: 12590622]

van Minnen A, Hoogduin K, Keijsers G, Hellenbrand I, Hendriks GJ. Treatment of trichotillomania with behavioral therapy or fluoxetine. Archives of General Psychiatry. 2003; 60:517-522. [PubMed: 12742873]

Wetterneck, CT.; Woods, DW. A Contemporary Behavior Analytic Model of Trichotillomania. In: Woods, DW.; Kanter, JW., editors. Understanding behavior disorders: a contemporary behavioral perspective. Reno, NV: Context Press; 2007. p. 157-180.

Wetterneck CT, Woods DW, Norberg MM, Begotka AM. The social and economic impact of TTM. Behavioral Interventions. 2006; 21:97-109.

Winchel RM. Trichotillomania: presentation and treatment. Psychiatric Annals. 1992; 22:84-89.

Winchel RM, Jones JS, Stanley B, Molcho A, Stanley M. Clinical characteristics of trichotillomania and its response to fluoxetine. Journal of Clinical Psychiatry. 1992; 53:304-308. [PubMed: 1517191]

Woods DW, Flessner CA, Franklin ME, Keuthen NJ, Goodwin RD, Stein DJ, et al. The trichotillomania impact project (TIP): exploring phenomenology, functional impairment, and treatment utilization. The Journal of Clinical Psychiatry. 2006; 2006:1877-1888. [PubMed: 17194265]

Woods, DW.; Twohig, MP. Trichotillomania: An ACT-enhanced behavior therapy approach (therapist guide). New York: Oxford University Press; 2008.

Woods DW, Twohig MP, Flessner CA, Roloff TE. Treatment of Vocal Tics in Children With Tourette Syndrome: Investigating the Efficacy of Habit Reversal. Journal of Applied Behavior Analysis. 2003; 36:109-112. [PubMed: 12723873]

Woods DW, Wetterneck CT, Flessner CA. A controlled evaluation of acceptance and commitment therapy plus habit reversal for trichotillomania. Behaviour Research and Therapy. 2006; 44:639_ 656. [PubMed: 16039603]

Zuchner S, Cuccaro ML, Tran-Viet KN, Cope H, Krishnan RR, Pericak-Vance MA, et al. SLITRK1 mutations in trichotillomania. Moleculear Psychiatry. 2009; 11:888-891.

Zuchner S, Wedland JR, Ashley-Koch AE, Collins AL, Tran-Viet KN, Quinn K, et al. Multiple rare SAPAP3 missense variants in trichotillomania and OCD. Moleculear Psychiatry. 2009; 14:6-9. 